\title{
Gynecological Surgical Procedure
}

National Cancer Institute

\section{Source}

National Cancer Institute. Gynecological Surgical Procedure. NCI Thesaurus. Code C15332.

Surgery performed on the female reproductive system. 